Research Report

\title{
DEPRESSION AND ANXIETY SYMPTOMS IN PSORIASIS PATIENTS COMPARED TO A CONTROL GROUP WITHOUT PSORIASIS-A DESCRIPTIVE STUDY
}

\author{
Sethulakshmi Sreevalsam Anil ${ }^{*}$, Pankajakshan Vijayanthi Indu ${ }^{2}$, Vidyadharan Suja ${ }^{3}$, Anuja \\ Elizabeth George ${ }^{4}$, Prabhakaran Anil ${ }^{5}$ \\ ${ }^{1}$ Consultant Psychiatrist, Ernakulam \\ ${ }^{2}$ Additional Professor in Psychiatry, Government Medical College, Kozhikode \\ ${ }^{3}$ Professor \& Head, Department of Dermatology, Sree Gokulam Medical College \& Research Centre \\ ${ }^{4}$ Professor of Dermatology, Government Medical College, Thiruvananthapuram \\ ${ }^{5}$ Professor \& Head, Department of Psychiatry, Government Medical College, Thiruvananthapuram \\ Correspondence; dr.sethulakshmi.s.anil@gmail.com
}

First submitted: 1/6/2019 Published online; 14/8/2019

\section{ABSTRACT}

Background: Due to psychosocial and neurobiological reasons, psoriasis is frequently associated with depression and anxiety. The aim of this study was to compare the occurrence of depression and anxiety symptoms in patients with psoriasis with a control group without psoriasis. It was also aimed to study the correlates of these psychological symptoms in patients with psoriasis.

Methods: A cross-sectional, comparison study was done on patients with psoriasis $(\mathrm{N}=35)$ and a control group $(\mathrm{N}=23)$, who were patients from Otorhinolaryngology department or their caregivers, without psoriasis, attending a tertiary care centre. In the study group, the severity of psoriasis, quality of life, depression and anxiety symptoms were assessed using the Psoriasis Area and Severity Index (PASI), Dermatology Life Quality Index (DLQI), Patient Health Questionnaire-9 (PHQ-9) and Generalized Anxiety Disorder-7 scale (GAD-7) respectively.

Results: $57.1 \%$ of cases $(95 \% \mathrm{CI}=39.52-73.24)$ were found to have symptoms of depression versus 8.7\% (95\% CI $=1.52-29.51)$ of controls $(\mathrm{p}<0.01) .45 .7 \%$ of cases $(95 \% \mathrm{CI}=29.22-63.12)$ had anxiety symptoms while it was absent in controls $(\mathrm{p}<0.01)$. No significant difference between the cases and controls were noted in other variables. Scores of PHQ-9 $(\rho=0.825, \mathrm{p}<0.01)$ and GAD-7 $(\rho=0.766, \mathrm{p}<0.01)$ were found to have a significant positive correlation with DLQI scores; higher scores suggestive of poorer quality of life. No significant correlation was found between the duration of psoriasis, PASI, PHQ-9 and GAD-7 scores.

Conclusion: There is a high prevalence of depressive and anxiety symptoms in patients with psoriasis compared to a control group without psoriasis. Psychological symptoms have a significant correlation with poorer quality of life of patients with psoriasis.

Keywords: Depressive disorder, anxiety disorders, dermatology, psoriasis, quality of life

Sethulakshmi S A, Indu P V, Suja V, Anuja E G, Anil P. Depression and anxiety symptoms in psoriasis patients compared to a control group without psoriasis-a descriptive study. Kerala Journal of Psychiatry 2018; 31(2): 71-

79. doi: 10.30834/KJP.31.2.2019.159 


\section{INTRODUCTION}

Psoriasis is a chronic, immune-mediated inflammatory skin disease. It ranges in severity from a few scattered red, scaly plaques to involvement of almost the entire body surface. The prevalence of psoriasis in India ranges from 0.44 to $2.8 \%{ }^{1}$ It may progressively worsen with age or wax and wane in its severity; the degree of severity depends on inheritance and environmental factors. ${ }^{2}$ Psoriatic patients often feel impaired by their physical appearance, leading to stigmatisation, avoidance of social interaction and isolation. This disease is frequently comorbid with psychiatric conditions like adjustment disorder, depressive disorder, dysthymia and anxiety disorders, which produces a significant impact on the psychological and social aspects of the patient's life. ${ }^{3}$

Gascón et al., in their study of hospitalised dermatology patients, found that $45.3 \%$ and $52 \%$ of psoriatic patients suffered from depression and anxiety symptoms, respectively $(\mathrm{N}=75) .{ }^{4}$ In a study done in Jodhpur, India, Kumar et al. found that $84 \%$ of psoriasis patients $(\mathrm{N}=50)$ had psychiatric morbidity. ${ }^{5}$ In this study $52 \%$ of psoriatic patients had mild anxiety, $36 \%$ had mild to moderate anxiety, and $12 \%$ had moderate to severe anxiety; whereas $68 \%$ of them had mild depression, $18 \%$ had moderate depression, $4 \%$ had severe depression, and $10 \%$ had minimal or no depression. Singh et al., using the Mini International Neuropsychiatric Interview (MINI), was able to diagnose depressive disorders in $39.4 \%$ of patients with mild to moderate psoriasis $(n=104)$ attending an outpatient clinic in the Department of Dermatology at a tertiary care centre in
Chandigarh. ${ }^{6}$ In a cross-sectional study done; 73-79in Puducherry, Lakshmy et al. found $78.9 \%$ and $76.7 \%$ of a sample of 90 psoriatic patients attending the department of Dermatology to be suffering from depression and anxiety symptoms respectively. ${ }^{7}$

None of these studies had compared the occurrence of depressive and anxiety symptoms in psoriasis patients with a control group. Hence, this study was undertaken to compare the depressive and anxiety symptoms among patients with psoriasis and controls without psoriasis at a tertiary care centre; and, to study the socio-demographic and clinical correlates of depressive and anxiety symptoms in this population.

\section{MATERIALS AND METHODS}

A cross-sectional, comparison study was undertaken over four months (June to September 2016) in a tertiary care teaching hospital in Thiruvananthapuram, Kerala. Cases were those aged 18-64 years, diagnosed with psoriasis, by the dermatologist in the Department of Dermatology of the tertiary care centre. Controls were selected from among patients attending the Department of Otorhinolaryngology of the same institution or their caregivers, without psoriasis. The patients from that department were diagnosed to have diseases like allergic rhinitis, rhinosinusitis, deviated nasal septum, chronic suppurative otitis media, polyps, thyroglossal cyst, carcinoma etc. Subjects with other comorbid skin disorders or with a history of previously diagnosed mental disorder other than alcohol use disorder and tobacco use disorder were excluded from the study. Approval was obtained from the Institutional 
Research Committee and Human Ethics Committee of the institution, prior to the study. All consecutive cases and concurrent controls were included in the study. Written informed consent was obtained from all the participants.

Taking $\alpha$-error as $5 \%, \beta$-error as $10 \%$, the prevalence of anxiety symptoms among cases (p1) as $76.7 \%{ }^{7}$ and in the normal population (p2) as $20.7 \%^{8}$, the sample size was calculated to be 19. With pl for depressive symptoms as $78.9 \%^{7}$ and p 2 as $15.1 \%^{8}$, it was 14 . Hence, the sample size of 35 cases and 20 controls were considered adequate for the study.

\section{Variables}

Depressive symptoms were assessed using the Patient Health Questionnaire-9 (PHQ-9). This is a 9-item self-report tool used for screening, diagnosing, monitoring and measuring the severity of depression. Each item is scored from 0 to 3 , and the total score ranges from 0 to 27 . The overall score is categorised as follows: 5-9: minimal symptoms; 10-14: major depression, mild; 1519: major depression, moderately severe; $>20$ : major depression, severe. It is a valid and reliable tool with a Cronbach's alpha of $0.89 .{ }^{9}$ The Malayalam version, as provided by the authors, was used. ${ }^{10}$

Anxiety symptoms were assessed using the Generalized Anxiety Disorder-7 (GAD-7) scale. It is a 7-item self-reported questionnaire for screening and measuring the severity of generalised anxiety disorder (GAD). Each item is scored from 0 to 3 , and the total score ranges from 0 to 21 . Scores of 5,10 , and 15 represent cut-off points for mild, moderate, and severe anxiety, respectively. It is a valid and reliable tool with a Cronbach's alpha of
0.89. ${ }^{11}$ The Malayalam version, as provided by the authors, was used. ${ }^{12}$

Socio-demographic variables including age, sex, marital status, education, socioeconomic status and occupation were assessed. Clinical variables like the duration of psoriasis, it's severity, quality of life, other chronic medical conditions, family history of depressive or anxiety disorder and the presence of alcohol or tobacco use disorder diagnosed as per the Diagnostic and Statistical Manual of Mental Disorders, $5^{\text {th }}$ edition (DSM-5) were studied. ${ }^{13}$ The severity of psoriasis was assessed using the Psoriasis Area and Severity Index (PASI). It combines the severity of the lesions and area affected into a single score ranging from 0 to 72 . It is a valid and reliable measure of the severity of psoriasis (Cronbach's alpha- >0.9). ${ }^{14}$ The quality of life of the psoriatic patient was assessed using the Dermatology Life Quality Index (DLQI). The DLQI is a compact self-reported questionnaire consisting of 10 items to measure health-related quality of life over the previous week in patients with skin diseases. ${ }^{15}$ The total score ranges from a minimum of 0 to a maximum of 30 , with higher scores indicating greater impairment in healthrelated quality of life. It has also been found to be valid and reliable in patients with psoriasis with a Cronbach's alpha of $0.83 .^{16}$ The Malayalam version of the DLQI, as provided by the authors, was used. ${ }^{17}$ Permission and the license for use were obtained from the authors of DLQI for the study.

All consecutive cases and concurrent controls were included in the study after obtaining informed consent. Details of the sociodemographic and clinical variables were 
obtained from the participants using a structured questionnaire and the tools described above, by the researcher. The assessment of the severity of psoriasis using
PASI was done by the dermatologist. Those found to have moderate to severe depression or anxiety symptoms were referred for further care to the department of Psychiatry.

Table 1. Distribution of Sociodemographic variables among cases and controls

\begin{tabular}{|c|c|c|c|c|}
\hline & & Cases $(n=35)$ & Controls $(n=23)$ & \multirow{2}{*}{$\chi^{2}(\mathrm{P}$ value $)$} \\
\hline & & \multicolumn{2}{|c|}{ Frequency (\%) } & \\
\hline \multirow{6}{*}{ Age } & $<20$ years & $1(2.9)$ & $0(0.0)$ & \multirow{6}{*}{$0.958^{*}$} \\
\hline & $21-30$ years & $2(5.7)$ & $1(4.3)$ & \\
\hline & $31-40$ years & $4(11.4)$ & $2(8.7)$ & \\
\hline & $41-50$ years & $14(40.0)$ & $8(34.8)$ & \\
\hline & $51-60$ years & $8(22.9)$ & $8(34.8)$ & \\
\hline & $>60$ years & $6(17.9)$ & $4(17.4)$ & \\
\hline \multirow{2}{*}{ Sex } & Male & $25(71.4)$ & $16(69.6)$ & \multirow{2}{*}{$\begin{array}{c}0.023 \\
(0.879)\end{array}$} \\
\hline & Female & $10(28.6)$ & $7(30.4)$ & \\
\hline \multirow{2}{*}{ Socioeconomic status } & Above poverty line & $15(42.9)$ & $6(26.1)$ & \multirow{2}{*}{$\begin{array}{c}1.69 \\
(0.194)\end{array}$} \\
\hline & Below poverty line & $20(57.1)$ & $17(73.9)$ & \\
\hline \multirow{5}{*}{ Marital Status } & Married & $31(88.6)$ & $19(82.6)$ & \multirow{5}{*}{$0.513^{*}$} \\
\hline & Unmarried & $2(5.7)$ & $1(4.3)$ & \\
\hline & Divorced & $0(0.0)$ & $0(0.0)$ & \\
\hline & Separated & $1(2.9)$ & $0(0.0)$ & \\
\hline & Widow/ Widower & $1(2.9)$ & $3(13)$ & \\
\hline \multirow{6}{*}{ Education } & Illiterate & $1(2.9)$ & $0(0.0)$ & \multirow{6}{*}{$0.478^{*}$} \\
\hline & Primary & $7(20.0)$ & $2(8.7)$ & \\
\hline & Upper primary & $7(20.0)$ & $3(13.0)$ & \\
\hline & High School & $11(31.4)$ & $13(56.5)$ & \\
\hline & Pre-degree & $4(11.4)$ & $3(13.0)$ & \\
\hline & Undergraduate & $5(14.3)$ & $2(8.7)$ & \\
\hline \multirow{5}{*}{ Occupation } & Unemployed & $12(34.3)$ & $5(21.7)$ & \multirow{5}{*}{$0.104^{*}$} \\
\hline & Unskilled & $6(17.1)$ & $11(47.8)$ & \\
\hline & Semi-skilled & $13(37.1)$ & $6(26.1)$ & \\
\hline & Skilled & $4(11.4)$ & $1(4.3)$ & \\
\hline & Professional & $0(0.0)$ & $0(0.0)$ & \\
\hline
\end{tabular}

*Fisher's exact test applied 
Table 2. Comparison of anxiety and depressive symptoms among cases and controls

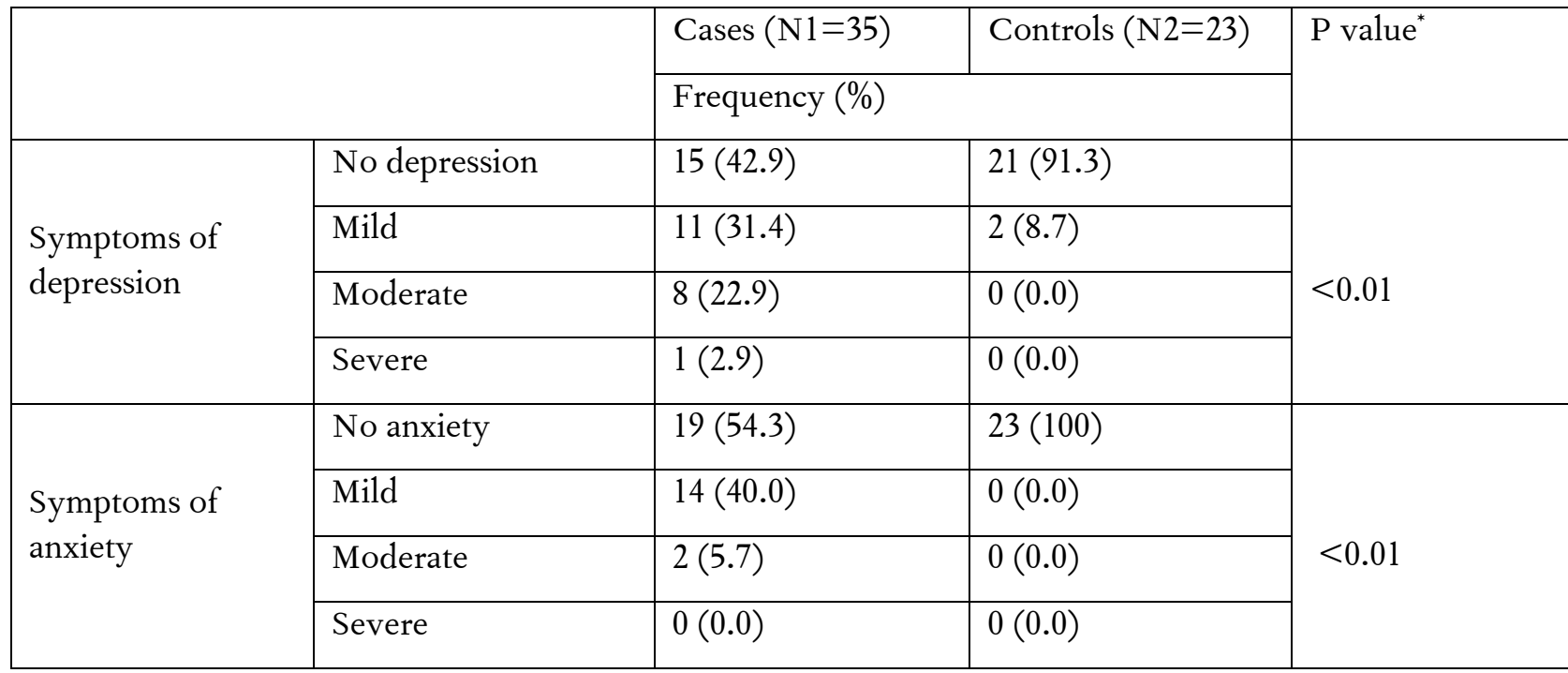

*Fisher's exact test applied

Table 3. Correlation between the scores of PHQ-9, GAD-7, PASI and DLQI and duration of psoriasis (DOP)

\begin{tabular}{|l|l|l|l|l|l|}
\hline Variable & PHQ-9 & GAD-7 & PASI & DLQI & DOP \\
\hline PHQ -9 & - & & & & \\
\hline GAD -7 & ${ }^{*} 0.871(<0.01)$ & - & & & \\
\hline PASI & $0.293(0.09)$ & $0.178(0.31)$ & - & & \\
\hline DLQI & ${ }^{*} 0.825(<0.01)$ & ${ }^{*} 0.766(<0.01)$ & ${ }^{*} 0.436(<0.01)$ & - & \\
\hline DOP & $0.157(0.37)$ & $0.200(0.25)$ & $-0.050(0.78)$ & $0.118(0.50)$ & - \\
\hline
\end{tabular}

Spearman's correlation coefficient ( $\mathrm{p}$ value) shown in the table. ${ }^{*} \mathrm{p}$ value $<0.0$

\section{RESULTS}

Data were entered in Microsoft Excel Version

7, cleaned and edited. Mean, and Standard Deviation (SD) of continuous variables and proportion for discrete variables are provided. The correlation was assessed using Spearman's correlation coefficient. R Version 2.13.1 was used for statistical analysis.

There were 35 cases and 23 controls in the study. The mean age for cases was 48.09 years [Standard Deviation (SD)-11.3], and that of controls was 50.87 years (SD-10.61). Majority of the cases belonged to the age group of 41-50 years (40\%), and controls belonged to both $41-50$ years and 51-60 years
(34.8\%). Majority of the cases and controls were males ( $71.4 \%$ and $69.6 \%$ respectively), belonged to lower socioeconomic status (57.1\% and $73.9 \%$ respectively), were married ( $88.6 \%$ and $82.6 \%$ respectively) and educated up to high school (31.4\% and $56.5 \%$ respectively). $37.1 \%$ of the cases were semiskilled workers, whereas $47.8 \%$ of the controls were unskilled labourers. (See Table.1).

Alcohol use was reported in $48.6 \%$ of cases and $43.4 \%$ of controls while tobacco was used by $45.7 \%$ of cases and $39.1 \%$ of controls. Chronic medical conditions like hypertension, dyslipidemia, diabetes mellitus 
etc. were reported in $28.6 \%$ of cases and $26.1 \%$ of controls. We did not find any significant difference between cases and controls in any of these variables. None of the participants gave a family history of depressive or anxiety disorders. The mean duration of psoriasis was 2.26 years (SD-1.50) with most cases suffering from psoriasis for 1-5 years $(34.4 \%)$. Those suffering from psoriasis for $5-10$ years constituted $22.9 \%$; $10-15$ years, $17.1 \%$; more than 20 years, $14.3 \%$; and less than one year as well as $15-20$ years, $5.7 \%$ each. The mean scores for PASI and DLQI were 12.75 (SD-9.62) and 10.83 (SD-5.60), respectively.

Depressive symptoms were reported by $57.1 \%$ of cases $[95 \%$ Confidence interval $(\mathrm{CI})=39.52-$ $73.24]$ and $8.7 \%$ of controls $(95 \% \mathrm{CI}=1.52-$ 29.51) $(p<0.01)$. Only mild depressive symptoms were reported by controls. The mean PHQ-9 score for cases and controls were 5.97 (SD-4.56) and 1.43 (SD-1.59), respectively. The mean GAD-7 score for cases and controls were 3.77 (SD-3.06) and 0.57 (SD-1.08), respectively. Anxiety symptoms were present in $45.7 \%$ of cases $(95 \% \mathrm{CI}=$ $29.22 \%-63.12 \%$ ) and none of the controls $(p<0.01) .40 .0 \%$ of cases were found to have mild symptoms of anxiety. (See Table 2 for details).

Correlation of socio-demographic and clinical variables with the duration of psoriasis, PASI, PHQ-9, GAD-7 and DLQI were assessed using Spearman's coefficient, but none of these was statistically significant. The correlation was also assessed between duration of psoriasis, PHQ-9, GAD-7, PASI and DLQI scores. DLQI scores were found to have a significant positive correlation with the PHQ-9 $(\rho=0.825, \mathrm{p}<0.01)$ and GAD-7 $(\rho=0.766, \mathrm{p}<0.01)$ scores, which suggested that more severe depressive and anxiety symptoms correlated with poorer quality of life. Significant positive correlations were found between DLQI and PASI scores $(\rho=0.436, \mathrm{p}<0.01)$ and between PHQ-9 and GAD-7 scores $(\rho=0.871, \quad \mathrm{p}<0.01)$. No significant correlation was found between other variables. See Table 3 for details.

\section{DISCUSSION}

In our study, $57.1 \%$ and $45.7 \%$ of patients with psoriasis were found to suffer from symptoms of depression and anxiety, respectively. In various cross-sectional studies, the prevalence of depression and anxiety in patients with psoriasis has ranged from $9.9-78.9 \%$ and $13.1-76.7 \%$ respectively. ${ }^{8,18}$ Dowlatshahi et al., in their systematic review and meta-analysis of literature, found a pooled prevalence of $28 \%$ for depressive symptoms; $12 \%$ and 19\% were suffering from a depressive disorder, diagnosed as per ICD-10 and DSM- IV respectively. ${ }^{19}$ However, Korkoliakou et al. in their case-control study were unable to find a significant difference between depression and anxiety in patients with psoriasis when compared with controls. ${ }^{20}$ Assessing for depressive and anxiety symptoms as against depressive and anxiety disorders as well as differences in the scales used could be the reasons for the wide variance in prevalence in these studies. In our study, we had assessed for depressive, and In this study, depressive and anxiety symptoms were found to correlate significantly with poorer quality of life in psoriatic patients. Similar findings were found in various other studies. ${ }^{8,18,21,22} \mathrm{~A}$ significant positive correlation was observed between the severity of psoriasis (PASI) and quality of life scores in our 
study. The literature search also concurred with studies that have established this relationship. ${ }^{8,23,24,25}$ However, Fortune et al. and Yang et al. were not able to establish a relationship between the severity of psoriasis and quality of life in patients with psoriasis. ${ }^{26,27}$ In a review, Aurangabadkar suggested that the psychosocial comorbidities of psoriasis are not always proportional to measures of disease severity. ${ }^{28}$ In our study also, no significant correlation was observed between the severity of psoriasis and depressive $\&$ anxiety symptoms.

We were not able to find any correlation between the other socio-demographic and clinical variables with our study variables like quality of life and depressive and anxiety symptoms. Other studies have found that psoriatic patients who were older and belonging to female sex were more prone to depression and anxiety ${ }^{18,23,29,30}$ However some studies have found that younger age increases the risk for depression in patients with psoriasis ${ }^{31,32}$ Quality of life was also found to be poorer in females with psoriasis. ${ }^{23}$ Lack of higher education and occupational inactivity were found to correlate with depressive symptoms in this population. ${ }^{29}$ Akayet al. $(\mathrm{N}=120)$ did not find any correlation between depression and duration of symptoms of psoriasis which concurred with our study. ${ }^{33}$ Our study found that psychological problems in psoriatic patients can impair their quality of life.

The limitation of our study is that it is a crosssectional study, and hence, causal inferences cannot be made. Since this is a hospital-based study, the findings lack generalizability. Assessment based on the type of psoriasis was not done; so also, a heterogeneous group was taken as controls for this study. A homogeneous control group consisting of patients with chronic medical conditions could have provided a better comparison.

Our study highlights that there is a high prevalence of anxiety and depression in patients with psoriasis compared to those without the disease. The severity of depression and anxiety showed a significant positive correlation with poorer quality of life of these patients. Therefore, it is important to assess and manage psychological symptoms in psoriatic patients to improve their quality of life. Longitudinal studies will help in developing a better understanding of the incidence and course of depression and anxiety symptoms in this population. Further studies on the management of psychological symptoms in this population will be of much value in the care of patients with psoriasis.

\section{REFERENCES}

1. Lebwohl M. Psoriasis. Lancet 2003; 361:1197-204.

2. Rapp SR, Feldman SR, Exum ML, Fleischer AB, Reboussin DM. Psoriasis causes as much disability as other major medical diseases. J Am Acad Dermatol 1999; 41:401-

3. 7. Dogra S, Yadav S. Psoriasis in India: Prevalence and pattern. Indian J Dermatol Venereol Leprol 2010; 76:595.

4. Gascón MRP, Ribeiro CM, Bueno LM de A, Benute GRG, Lucia MCS de, Rivitti EA, et al. Prevalence of depression and anxiety disorders in hospitalised patients at the dermatology clinical ward of a university hospital. An Bras Dermatol 2012; 87:4037.

5. Kumar S, Kachhawha D, Koolwal GD, Gehlot S, Awasthi A. Psychiatric morbidity in psoriasis patients: A pilot study. Indian J Dermatol Venereol Leprol 2011; 77:625.

6. Singh SM, Narang T, Dogra S, Verma AK, Gupta S, Handa S. Screening for depressive disorders in 
outpatients with mild to moderate psoriasis: A study from North India. Indian J Dermatol Venereol Leproh2015; 81:148-50.

7. Lakshmy S, Balasundaram S, Sarkar S, Audhya M, Subramaniam E. A cross-sectional study of prevalence and implications of depression and anxiety in psoriasis. Indian J Psychol Med 2015; 37:434-40.

8. Reddy VM, Chandrashekar CR. Prevalence of mental and behavioural disorders in India: a metaanalysis. Indian J Psychiatry 1998; 40:149-57.

9. Kroenke K, Spitzer RL, Williams JB. The PHQ-9: Validity of a brief depression severity measure. J Gen Intern Med 2001; 16:606-13.

10. PHQ 9-Malayalam [Internet]. [cited 2018 Sep 6]. Available from:

http://www.phqscreeners.com/sites/g/files/g1001 6261/f/201412/PHQ9_Malayalam\%20for\%20India. pdf

11. Löwe B, Decker O, Müller S, Brähler E, Schellberg D, Herzog W, et al. Validation and standardisation of the Generalized Anxiety Disorder Screener (GAD-7) in the general population. Med Care 2008; 46:266-74.

12. GAD-7 - Malayalam [Internet]. [cited 2018 Sep 6]. Available from: http://www.phqscreeners.com/sites/g/files/g1001 6261/f/201412/GAD7_Malayalam\%20for\%20India. pdf

13. American Psychiatric Association. Diagnostic and Statistical Manual of Mental Disorders: DSM-5. Arlington, VA: American Psychiatric Association, 2013.

14. Langley RG, Ellis CN. Evaluating psoriasis with Psoriasis Area and Severity Index, Psoriasis Global Assessment, and Lattice System Physician's Global Assessment. J Am Acad Dermatol 2004; 51:563-9.

15. Finlay AY, Khan GK. Dermatology Life Quality Index (DLQI)-a simple, practical measure for routine clinical use. Clin Exp Dermatol 1994; 19:210-6.

16. Mazzotti E, Barbaranelli C, Picardi A, Abeni D, Pasquini P. Psychometric properties of the Dermatology Life Quality Index (DLQI) in 900 Italian patients with psoriasis. Acta Derm Venereo/2005; 85:409-13.
17. DLQI-Malayalam [Internet]. [cited 2018 Sep 6]. Available from: http://www.cardiff.ac.uk/dermatology/files/2014/ 07/DLQI-Malayalam.pdf

18. Lamb RC, Matcham F, Turner MA, Rayner L, Simpson A, Hotopf $\mathrm{M}$, et al. Screening for anxiety and depression in people with psoriasis: a crosssectional study in a tertiary referral setting. $\mathrm{Br} J$ Dermatol 2017; 176:1028-34.

19. Dowlatshahi EA, Wakkee M, Arends LR, Nijsten T. The prevalence and odds of depressive symptoms and clinical depression in psoriasis patients: A systematic review and meta-analysis. J Invest Dermatol 2014; 134:1542-51.

20. Korkoliakou P, Christodoulou C, Kouris A, Porichi E, Efstathiou V, Kaloudi E, et al. Alexithymia, anxiety and depression in patients with psoriasis: A case-control study. Ann Gen Psychiatry 2014; 13:38.

21. Tee SI, Lim ZV, Theng CT, Chan KL, Giam YC. A prospective cross-sectional study of anxiety and depression in patients with psoriasis in Singapore. $J$ Eur Acad Dermatol Venereo12016; 30:1159-64.

22. Martínez-García E, Arias-Santiago S, ValenzuelaSalas I, Garrido-Colmenero C, García-Mellado V, Buendía-Eisman A. Quality of life in persons living with psoriasis patients. J Am Acad Dermatol 2014; 71:302-7.

23. Petraškienè R, Valiukevičienè S, Macijauskienè J. Associations of the quality of life and psychoemotional state with sociodemographic factors in patients with psoriasis. Medicina (Kaunas) 2016; 52:238-43.

24. Gelfand JM, Feldman SR, Stern RS, Thomas J, Rolstad T, Margolis DJ. Determinants of quality of life in patients with psoriasis: A study from the US population. J Am Acad Dermatol 2004; 51:704-8.

25. Rakhesh SV, D’Souza M, Sahai A. Quality of life in psoriasis: a study from south India. Indian $J$ Dermatol Venereol Leprol 2008; 74:600-6.

26. Fortune DG, Main CJ, O'Sullivan TM, Griffiths CE. Quality of life in patients with psoriasis: the contribution of clinical variables and psoriasisspecific stress. Br J Dermatol 1997; 137:755-60. 
27. Yang Y, Koh D, Khoo L, Nyunt SZ, Ng V, Goh CL. The psoriasis disability index in Chinese patients: contribution of clinical and psychological variables. Int J Dermatol 2005; 44:925-9.

28. Aurangabadkar SJ. Comorbidities in psoriasis. Indian J Dermatol Venereol Leprol 2013; 79:10-7.

29. Pietrzak D, Pietrzak A, Krasowska D, MakaraStudzińska M, Madej A, Baranowska M, et al. Depressiveness, measured with Beck Depression Inventory, in patients with psoriasis. $J$ Affect Disord 2017; 209:229-34.

30. Sampogna F, Chren MM, Melchi CF, Pasquini P, Tabolli S, Abeni D, et al. Age, gender, quality of life and psychological distress in patients hospitalised with psoriasis. Br J Dermatol 2006; 154:325-31.

31. Kim GE, Seidler E, Kimball AB. Effect of age at diagnosis on chronic quality of life and long-term outcomes of individuals with psoriasis. Pediatr Dermatol 2015; 32:656-62.

32. Kurd SK, Troxel AB, Crits-Christoph P, Gelfand JM. The risk of depression, anxiety, and suicidality in patients with psoriasis: A population-based cohort study. Arch Dermatol 2010; 146:891-5.

33. Akay A, Pekcanlar A, Bozdag KE, Altintas L, Karaman A. Assessment of depression in subjects with psoriasis Vulgaris and lichen planus. J Eur Acad Dermatol Venereol 2002; 16:347-52. 